\title{
Are the kids alright? Exploring students' experiences of support mechanisms to enhance wellbeing on an engineering programme in the UK
}

Deesha Chadha*1, Andreas Kogelbauer ${ }^{1}$, James Campbell ${ }^{1}$, Klaus Hellgardt ${ }^{1}$, Marsha Maraj ${ }^{1}$, Umang Shah ${ }^{1}$, Clemens Brechtelsbauer ${ }^{1}$, Colin Hale ${ }^{1}$

* corresponding author, ${ }^{1}$ Imperial College London

Dr Deesha Chadha,

Senior Strategic Teaching Fellow, Department of Chemical Engineering, 1M17A ACEX, South Kensington Campus, Imperial College London, London, SW7 2 AZ.

Email: d.chadha@imperial.ac.uk

Phone: 0044 (0) 2075948958

Dr. Deesha Chadha is a senior strategic teaching fellow in the department of chemical engineering.

Dr. Andreas Kogelbauer is a senior lecturer and the senior academic tutor in the department of chemical engineering.

Dr James Campbell is a teaching fellow in the department of chemical engineering.

Professor Klaus Hellgardt is a professor of catalysis and the director of undergraduate studies in the department of chemical engineering.

Dr Marsha Maraj is a senior strategic teaching fellow in the department of chemical engineering.

Dr Umang Shah is a principal teaching fellow in the department of chemical engineering.

Dr Clemens Brechtelsbauer is director of engineering education in the department of chemical engineering.

Dr Colin Hale is a senior teaching fellow in the department of chemical engineering. 


\title{
Are the kids alright? Exploring students' experiences of support mechanisms to enhance wellbeing on an engineering programme in the UK
}

\begin{abstract}
In this paper, we aim to explore students' experiences of support mechanisms that support their wellbeing on an engineering degree programme at a research-intensive higher education institution and understand how theory relates to practice. This study was conducted using a mixed-methods approach involving student survey responses $(\mathrm{N}=173)$, interviews with 16 students and focus groups. Kahu and Nelson's conceptual framework was used as a lens through which to explore student support mechanisms. Preliminary data analysis indicates that the intense workload adversely affects students as do some of the interactions they have with personal tutors and their peers. Our findings suggest that workload needs to be reduced, personal tutors need to fill gaps in their skills set, especially associated with student support, and institutional and departmental protocols be continually updated to support student wellbeing. Additionally, student wellbeing officers and professional, dedicated wellbeing advisors could be part of a long-term solution.
\end{abstract}

\section{Keywords}

Chemical engineering, conceptual framework, peer support, student workload, tutor-student relationship, wellbeing

\section{Setting the scene}

This paper reports on research carried out on a chemical engineering degree programme, based at a UK research-intensive higher education institution (HEI) on support structures available to students, to safeguard their wellbeing. The student body in question, is comprised of high achieving individuals (who perform outstandingly in pre-university examinations), and the cohort is sizeable in number, with 120-150 students per year group of which approximately $25 \%$ are female and a large proportion (between $40-50 \%$ ) come from East Asia. The degree programme is intensive, with all lectures, tutorials and laboratory-based sessions taught over 2 terms. Students have deadlines for coursework, lab reports and project work, although most of their modules are assessed through end-of-year exams. Highachieving students like ours come across as competitive (Yip 2009), and as educators, there are concerns for students' general wellbeing, as they are equally as hardworking and overburdened, with such students often suffering from stress (Yip 2009; Smith 2019). Student support is fundamental in higher education, both academically and socially, as it acts as one of the most important mechanisms available to us as educators through which we can protect our students' wellbeing. Among engineering undergraduates, the problem is particularly acute with student stress being brought on by the low overall retention, difficult courses and intensive projects experienced by engineering students (Donowitz and Beddoes 2018). International examples from the Basque Country, Canada and South Africa point to the difficulties of deadlines, the intensity of assessment and the rupturing of routines as leading to increased stress among engineering students (Garmendia et al. 2008; Gerrard et al. 2017; 
Swart and Hertzog 2017). Findings from research in other disciplines highlights the relationship between wellbeing and workload with stress among students increasing as workloads intensify (Shaikh et al. 2004; Alzahem et al. 2011). More recent work by Smith (2019) in which he examined the relationship between workload and stress among 1294 university students, claimed that an increase in workload increases the amount of stress students face, with engineering students being a prime example of this (Godfrey and Parker 2010; Danowitz and Beddoes 2018).

A definition of wellbeing is clearly important here in light of the work being reported on in this paper. According to the World Health Organisation (WHO), a state of wellbeing is achieved when 'every individual realises his or her own potential, can cope with the normal stresses of life, can work productively and fruitfully, and is able to make a contribution to her or his community' (2012). This definition amounts to coping within the bounds of what is accepted as normal. In an educational context, a small number of studies have isolated wellbeing from student engagement and focused on developing a more specific conceptual understanding around student wellbeing. For example, Field (2009) connected successful learning with feelings of being well physically, socially and emotionally (the notion is similar to that expressed by the WHO, whereby one is essentially 'fine and getting on with things'). Ansari et al. (2011), explored the reciprocal relationship between three factors in developing their model of wellbeing - health, health behaviour (for example health awareness), and educational achievement. Both these definitions enable us to consider a more rounded view of wellbeing in education, incorporating physical, social and mental health meaning that a joined-up approach where advisors, educators, wellbeing advisors, peer groups, student wellbeing officers and the student themselves become responsible.

Coupled with a definition are indicators of wellbeing with trust being a key one, usually along with support from teachers and peers, and a sense of belonging (New Economic Foundation 2009). Trust and trusting relationships are beneficial in maintaining students' wellbeing, with students reportedly feeling safe in situations of mutual trust (Sebring and Bryk 2000). According to Leighton et al. (2016), it serves as a key element in building student-teacher and student-student relationships, comprising of 5 constructs that support wellbeing: benevolence, reliability, competence, honesty, and openness. Several disciplinebased studies highlight the importance of belonging and its impact on wellbeing (for example Alder 2016; Raymond and Sheppard 2018), with social networks - either with fellow students (peer-to-peer support) or those with mutual interests (student clubs), being instrumental in helping students cope with feelings of isolation (Ahn and Davis 2020). Social wellbeing depends upon the following factors: engaging in supportive relationships, trusting other people, enjoying respect, a sense of belonging and the importance of responsibility (Forgeard et al. 2011; Universities UK 2015). Zepke's contributing sensitising concepts (drawn from literature) and their associated mainstream applications (2015) with regards to wellbeing, provides us with more sophisticated ideas, in that he uses such phrases as 'understanding emotions' and 'trust in self and others' both of which require a level of maturity and introspection. Given this, common indicators of trust and feeling a sense of belonging makeup part of the support structure which enhances student wellbeing.

\section{Student support that leads to wellbeing through an appropriate conceptual framework}


The conceptual framework on student engagement developed by Kahu and Nelson (2017) incorporates notions of wellbeing and is potentially an excellent one through which we can explore the utility of our findings. The framework itself, stems from an earlier conceptual one (Kahu 2013), which showed wellbeing as a proximal consequence rather than as both a key ingredient of the educational interface and as an immediate outcome. Educators have become increasingly aware in recent times of the wellbeing support students require as they journey through their education and that students engage positively with their learning if they are emotionally invested in it (Zepke 2015). Equally, the higher a students' self-efficacy, the greater the likelihood of an increase in their sense of wellbeing, with the more externally engaged students (e.g. those that form close peer-to-peer associations) reporting higher levels of self-efficacy and wellbeing (Costa et al. 2013). In exploring the validity of the framework proposed, Kahu et al. (2017) discuss the relationship between situated learning or context, the learning environment and students' own emotions and sense of belonging through what they have labelled an educational interface (self-efficacy, emotions, belonging and wellbeing). At the educational interface of this framework, wellbeing correlates with behaviour (participation and interaction). Examples of activities which would represent this specific construct include making friends, joining clubs and societies, and creating time for leisure activities.

There is, however, considerable crossover among these four constructs, and self-efficacy, emotions and belonging also inform wellbeing. For example, even though belonging sits alongside wellbeing in the framework, students need to feel a sense of belonging to nurture good relationships with teachers and peers which greatly enhances their wellbeing (Zepke 2013). Student wellbeing can be considered a more central feature of the framework than it is currently shown to be, and as suggested by Kahu et al. (2017), 'at the heart of the interface is the student's engagement - their emotional, cognitive and behavioural connection to their study' (p.56). According to the framework, emotions affect learning, whereby specific emotions either spur students on or they inhibit their learning. For the purposes of this work, the conceptual framework on student engagement proposed by Kahu and Nelson has been adapted (Figure 1) to focus more explicitly on wellbeing. Our principal interest here is focused on the borderlines of these interfaces as this framework of student engagement can be adapted, based on evidence we have collated, to establish where support might be offered that directly leads to or enhances student wellbeing. What needs to happen or change between the psychosocial influences, sociocultural contexts and immediate outcomes with respect to the mechanisms currently in place that effectively supports student wellbeing? What might we conceivably imagine this new support offering to look like?

\section{[FIGURE 1 HERE]}

Currently, our institution has a protocol in place to support students academically and socially through peer group personal tutorials. Institutionally, we also have a peer-to-peer buddying system whereby 1st year students are buddied with another student from the year above who helps them settle in. End-of-year student evaluations have indicated a lack of take up and interest in the scheme, suggesting the need for further work in this area. 


\section{Methodological approach}

A qualitative methodological paradigm was considered through which to address our central research question: how should engineering educators be supporting their students' wellbeing? The question proposed is aimed at understanding students' experiences around wellbeing, with the findings being instrumental to developing more robust mechanisms that actively support the wellbeing needs of engineering students. A case study was adopted as the methodological approach through which this research was conducted (Stake 2010), with the case in point being support for wellbeing in an engineering programme whereby data was collected via student surveys (accounting for $34.6 \%$ of the student population), interviews and focus groups so findings could be triangulated (Flick 2007). It is a combination of the implicit concerns mentioned and the current measures in place in our department to support students that has provided an appropriate guide for drafting and refining our survey, interview and focus group questions (following consultation with staff and student representatives). Institutional ethical procedures were followed in conducting the research.

\section{Data collection}

A student survey (requiring agree-disagree responses on a 5-point Likert scale plus open-text comments whereby students were invited to add their own additional, personal comments if they so wished) was prepared and administered to current students, to solicit their responses on six items related to student support. The items of the survey were agreed among our undergraduate teaching team (made up of individuals reporting directly to the director of undergraduate programmes) and piloted with 2 undergraduate students. The survey was made available to students on-line (an email was sent with the link to the survey) and each year group was sent several reminders (once a week until the survey closed after approximately six weeks) to complete the surveys. Students were informed that their responses would be treated anonymously, in confidence and that if they submitted their survey, they were allowing their data to be used for research purposes. Students did not receive any specific incentive to participate in the research. In total, 189 students completed surveys of which 173 were useable according to Qualtrics (institutional survey software) - as 16 surveys were incomplete and therefore did not register on the system, accounting for $34.6 \%$ of the total number across the four years of our programme of study: year 1 (52), year 2 (39), year 3 (40), year 4 (22) and did not state (20).

Student interviews and focus groups provided us with the best tools for understanding the research participants' personal perceptions and to facilitate an open dialogue between the students and researcher (Kvale 1996). Students volunteered to participate with the interviews and focus groups, and were recruited through blanket emails (on the understanding their involvement would not affect their grades in line with ethical procedures), resulting in 16 student interviews (four students from each year group) and four student focus groups (four or five students attended a focus group from each year). It is difficult to say how representative these groups of students were, but the make-up of the group consisted of a mix of ethnicities, academic ability, and gender. Interviews were conducted by teaching fellows in the department who, at the time of data collection, had no teaching responsibilities and were 
unknown to the students. During interview sessions, students were asked several questions about their educational experience in general. The questions which related to support were 1. Tell me about the support you have day-today on the programme. 2. What are the positives and negatives around support? The format we followed was that of semi-structured interviews enabling follow-up questions to be asked, which essentially facilitated dialogue. The student interviewees represented what Crouch and McKenzie (2006) refer to as 'meaningful experience-structure links' as they are able to internalise and articulate their experiences of student support within the curriculum. Interviews took place in a staff common room, regarded as a safe space for students and lasted approximately 40 minutes. Focus group data was gathered by presenting students with several descriptors regarding their experience of their programme (for example collaborative, engaging etc.) which they were asked to prioritise and then collectively explore through dialogue with the researcher present. Focus group sessions took place in a seminar room and lasted approximately 1 hour.

\section{Data analysis}

Survey data was analysed using a software package, SPSS (statistical package for social sciences), and the Spearman Rank correlation coefficient calculated ${ }^{1}$ so as to determine the extent of correlation between the six items (presented as Table 1). With respect to the interview and focus group data collated, these were both recorded and transcribed in full (having sought students' permission) and then emailed through to the individual students so the transcript could be agreed. Once this process was completed, all transcripts underwent primary analysis, by having two individuals independently re-read the transcripts and search for similar comments/experiences that were broadly repetitive, so they could be coded and categorised by allowing categories to emerge from the data itself in accordance with the protocols on thematic analysis set out by Braun and Clarke (2012). These broad categories were then accommodated into major themes: student workload, peer interaction and tutorial support. A further secondary interpretive analysis of the qualitative data followed on from this leading to more refined coding and categorisation, enabling us to identify sub-themes: intensity of workload, student time management, peer mentoring, peer support, commitment from personal tutors and skills set of personal tutors - these were highlighted and compared with responses from the student survey data, to enhance the validity and reliability of our findings. We then evaluated our findings using Kahu and Nelson's conceptual framework on student engagement to develop our model for use on our programme and for wider discussion and dissemination. Our case study has led to some invaluable insights, which are evidenced in practice and from which others can learn beyond the scope of engineering.

\section{Results}

\section{Quantitative data results}

Quantitative data results have been presented as a synopsis in this paper for ease of reading. Figure 2 shows the percentages in student numbers who responded along the 5-item Likert

\footnotetext{
${ }^{1}$ Spearman Rho was selected so we could establish the monotonic relationship between 2 items, and not assume linearity. Both strength and direction of association could therefore be measured.
} 
scale (strongly agree, agree, neither agree nor disagree, disagree strongly disagree) to the six items ${ }^{2}$ on support in the curriculum.

\section{[FIGURE 2 HERE]}

Table 1 denotes the correlation coefficients of the 6-item scale on student support and related mechanisms. The quantitative analysis shows high degrees of association in some areas, for example suggesting positive relationships between staff and students, and between student peers with respect to enhancing wellbeing.

\section{[TABLE 1 HERE]}

Across UK HEIs, the role of the personal tutor (sometimes referred to as the academic tutor), is to provide tutorial support to their students. This means that tutors guide and council students should they need it, support their professional development and act as their first port of call should they have any general questions or personal concerns. They are academic members of staff who meet their tutees on a regular basis, and additionally oversee the wellbeing of these students. The 'Mums and Dads' scheme mentioned in this paper refers to a scheme set up through the Students Union and is a peer-to-peer mentoring scheme, whereby students from the year directly above a year group mentor one or two students from that year group. Open-text comments from the surveys have been included in the qualitative data results.

\section{Qualitative data results}

Our findings are presented under the following section headings:

- Student workload

- Peer interactions: peer mentoring and peer-to-peer support

1. Peer mentoring: The Mums and Dads scheme

2. Peer-to-peer support

- Tutorial support systems

Three major themes were identified from the analysis of our data, which were: student workload, peer interactions, and tutorial support systems. Our results and discussion are being presented collectively for ease of reading.

\section{Student workload}

Table 1 shows that there is a strong correlation between a balanced workload, support for wellbeing and peer interaction. The correlation between workload and peer interaction is not wholly unexpected as Kember (2004) discovered, claiming that 'by working together students can help each other understand difficult concepts. It also appeared that strong friendship groups within a class had some effect on mitigating perceptions of heavy workload' (p.179). Excerpts taken from interviews, particularly with first-year students point to difficulties they

\footnotetext{
${ }^{2}$ (1) Quality of support from personal tutor (2) Mums and Dads scheme (3) Organisation of programme (4) Balance of workload (5) Support for wellbeing (6) Social interaction with peers
} 
experience in maintaining a reasonable work-life balance, examples of which are provided with student A commenting on the high workload directly and student B on the heavy content and not having free time:

'The transition from high school was really well done, but then out of nowhere it suddenly changed to a really high workload, which was kind of surprising but expected at the same time ... Now we have a lot of deadlines in the next few weeks before the break. There are now a lot of lectures every single morning, plus we have labs, plus we have projects to do. Now it is just constant working even at the weekends, [with] no free time off.'

Interview comment, Student A, Eastern European, male $1^{\text {st }}$ year

'I think it's good now. I'm kind of satisfied, I'm quite satisfied. It's just heavy - the course itself is quite heavy. And there's kind of like a lot of free time which is not actually free time, it's like self-study time. I think it's more individual. You have to be on top of everything and not leave everything to the last minute.'

Interview comment, Student B, Chinese, female $2^{\text {nd }}$ year

Difficulties have always existed in managing the workload of both staff and students in engineering degrees, due to the often-rigid structures (of taught sessions and examination) of curriculum (Malm et al. 2012). In the UK, the content and structure of the degree programme is governed by accreditation requirements of the Institute of Chemical Engineers (IChemE). Graduate chemical engineers are expected to have awareness, knowledge, understanding, and skills in fundamental principles, core principles, chemical engineering practice, and chemical engineering design, at both basic and advanced levels of proficiency. To accommodate accreditation requirements, there is a tendency to overload the curriculum with programme and module outcomes which must then be fulfilled (Fitzpatrick et al. 2009). There is a lack of uniformity among accreditation bodies, with the added danger that with the onset of Brexit, the gap between UK-based accreditation systems and those in central Europe grows.

Previous research denotes and our findings concur, that students' sense of wellbeing is somewhat correlated to the burden of continual exams, assignments and presentations (Ansari et al. 2011) suggesting there is a deeper, fundamental importance in creating space in which students can reflect on their learning. However, students also place them themselves under pressure as much as the curriculum does, as stipulated in focus group and interview comments:

'Maybe one thing that isn't great is that it's quite hard to know the boundary of the coursework and the scope. It's very easy to spend excessive amounts of time on coursework without any limiting mechanism and that obviously affects you, especially when it's a very intense project and there are end goals that are clearly defined ... So that has a negative impact on mental health and other aspects of the course, that limiting factor.'

Interview comment, Student C, British, male, $3^{\text {rd }}$ year

'Spring term is pretty challenging and I've come to accept that even autumn term this year was hard work, but it's unlikely to be the same stress level as it is now the thing with a second 
year is that [a particular module] was significantly harder, and that is something I would reflect on, like I've never done any computational stuff before. I spent a really long time on it.'

Interview comment, Student D, British-Asian, male, $2^{\text {nd }}$ year

According to Kember (2004), the perception of a heavy workload is a feeling in the form of pressure and stress, and our findings suggest students place themselves under as much pressure as the curriculum itself seems to place them under. Students need to assume some responsibility here as it is, in part, their response to their workload that presents itself as internalised pressure. Literature also identifies the issue of cohort memory with students in higher years relating tails of their educational experiences to those in lower year groups, and so a repetitive cycle is formed (Verger et al. 2009).

\section{Peer interactions: peer mentoring and peer-to-peer support}

There are effectively two strands with respect to peer interaction, one is peer mentoring through the Mums and Dads scheme and the other is social interaction and day-to-day relationships with peers, including student wellbeing officers.

\section{Peer mentoring: The Mums and Dads scheme}

The Mums and Dads scheme does not currently work satisfactorily, although there are indicators (both from student interviews and the strong correlation between the scheme and programme organisation), that concerns are related to the organisation of the scheme rather than the scheme itself. Interview comments point to a lack of coherent organisation with respect to the scheme:

'The mums and dads' scheme were organised poorly this year ... In previous years we received much more information ahead of time. Also, there should be much more focus on the mums/dads' event, in my first year I saw my mum/dad once, in second year I saw my children twice. The scheme at the moment does not feel useful as there simply isn't enough encouragement for engagement.

Interview comment, Student E, British, female, $3^{\text {rd }}$ year

The underlying principle of the 'Mums and Dads' initiative is a good one as it actively encourages students to get over any natural feelings of homesickness and loneliness they may experience by creating a peer support group (Thurber and Walton 2012), although these only span two year groups (the parental year group and their allocated children). In one of the focus groups, it was clear that there were some positives with the scheme, and students could go to other students with problems, but that the relationships depended on personalities and how much time and effort was put into nurturing these relationships.

- 'The emphasis is more on the social side of the department because when we do our mums and dads event, we go for drinks to the student union and some stuff like that. I mean our kids have come to us with problems.

- Should students be in charge of other students' wellbeing? That's quite dangerous. 
- It's not really wellbeing, it's so they can talk about their issues.

- It should be mums and dad who approach because the kids don't do it.

Focus group responses, $4^{\text {th }}$ year students

In recent research, Maunder (2017) reported that there was a direct correlation between students who had good relationships with their peers and their adjustment to university. The scheme we currently have in place, was setup by the institutional student union and is flexibly framed, although additional student comments from the survey suggests an ad-hoc approach which achieves little tangible benefit as it lacks a coherent structure and its value is unclear.

\section{Peer-to-peer support}

Peer-to-peer interaction was another important feature highlighted from our initial data analysis. Students are broadly satisfied with the interactions they have with peers, although additional student comments point to a culture of competition, as well as a lack of peer-topeer support which can equally add to the pressures of performance many high achieving students face (Andrews and Wilding 2004). Student responses are included:

'Very little concern for mental health, which is a problem, because a lot of students have problems coping, and not just with the workload, but working together. It's a very competitive environment.'

Open-text comment

'The reason it's worth more than a degree from somewhere else is because it's [X] and it's going to be harder and more competitive and that's fine, but it's the way everyone goes around acting like they're so hard done by, like this course is out to get them. We chose to be here, and I don't know how you change that - that's the problem. People just need to take a chill pill.'

$$
\text { Interview comment, Student F, British, female, } 3^{\text {rd }} \text { year }
$$

A second aspect of peer-to-peer support is that student wellbeing officers are nominated to support their peers' by providing wellbeing support, as much as this is possible (they receive limited training), as part of the institutional policy. Students commented on the role and remit of the student wellbeing officers in focus group sessions:

- 'The wellbeing day was nice where they just brought in cookies and milk. But why have they only got one wellbeing day all year?

- I think that's the organisers who are still trying to work out what they're going to do with it.

- It was like, I was ill that day, so I don't get any wellbeing.

- Because they had a suggestion box for things that they could implement around the department and that was the main reason for the wellbeing day.'

Focus group responses, $2^{\text {nd }}$ year students

- 'I think for me the thing about wellbeing is that people in the $1^{\text {st }}$ year come at 9am for lectures, stay all day, they are in the library until midnight which is just crazy. To do that every day for a few weeks, you're going to start feeling quite depressed. I think the [student] wellbeing officer idea is a useful one in this respect because we all understand what it feels 
like. Also, I think encourage people to spend less time at university because it's not such a big thing.'

Focus group responses, $3^{\text {rd }}$ year students

Students are likely to seek help from their peers to support their wellbeing needs in the first instance (Laidlaw et al. 2016) so there is potential added value in having student wellbeing officers. However, the scheme is still in its infancy resulting in no clear remit for the role, although it is generally understood that there are positive benefits of peer mentoring in this way, in helping students with retention, wellbeing and integration (Collings et al. 2014). The findings suggest that we will need to look towards a more robust hybrid model between designated peer student wellbeing officers and the 'Mums and Dads' scheme.

\section{Tutorial support systems}

The data suggests that students are conscious of the need to have a good relationship with their personal tutors to seek support, although somewhat equate (in their own minds at least) the quality of the relationship with tutors having time for them:

'My tutors are excellent, but they are extremely busy. Sometimes I wish I had someone who could dedicate more time (up to an hour) every month in a one-to-one meeting. I'd benefit from being able to really talk regularly about how I'm doing, and how I can reach my goals and overcome my challenges.'

Open-text comment

'Some tutors are more present and helpful than others, and it's difficult to get as much support from tutors who are less involved.'

Open-text comment

Focus group responses also highlighted the significance of the student-tutor relationship. From the transcript, it is implied that students are reactive rather than proactive in terms of nurturing the relationship and setting the expectations, although we might envisage the nature of the relationship changing as students' progress through the programme:

- 'I go to my personal tutor. I was ill and I went to my personal tutor.

- I would not go to my personal tutor for anything. He starts off 'in my days when I go to university' and then we end up somewhere completely different, which is useless. I respond to the system's cues so if they say that your personal tutor is there to talk to you about personal issues then that's the cue I follow. We were told about all these resources, but unless my complaint is very specific, I don't feel like I can go anywhere.

- I feel detached from it and that I can't really make any change.'

Focus group responses, $1^{\text {st }}$ year students

- 'They need to do better signposting with wellbeing. It is an issue, but I don't think that it's the departments' sole responsibility. People need to be pro-active and they need to create the environment, so people know where to go - we help ourselves and each other. The department can't provide the solution, but it can provide the information of where to go to seek a solution.' 
Focus group responses, $3^{\text {rd }}$ year students

The comment on responsibility is interesting and institutional policies also mostly reflect a joined-up approached which encompasses shared, collective responsibility (tutors, mental health advisors, students themselves, counsellors). Zepke (2013) concurs, acknowledging that even though teachers and HEIs are not solely responsible for student wellbeing, they can help students by maintaining a culture that supports wellbeing.

Focus group comments suggest that students appreciated the skills-set of the tutors is limited in terms of the support they can provide, especially with respect to supporting their personal issues:

- 'This is about wellbeing and we're talking about the personal tutors, but there's also a limit on what they can do because they are not the solution. That situation for them can be quite hard because they're not the right people.

- How would you improve wellbeing because that's a big topic?'

Focus group responses, $3^{\text {rd }}$ year students

- ' It would help if we had people to talk to. I know there are people to talk to, but it doesn't necessarily mean that you trust talking to them. If a lot of the lecturers or the senior members of staff were made more approachable and available. Like I know there's people to talk to. We get emails about it and stuff. They say 'oh you can always talk to this person' but I've never heard of this person. I don't trust talking to them.'

Focus group responses, $2^{\text {nd }}$ year students

Students need strong bonds with their personal (or academic) tutors so they can feel secure in the relationship and be reassured that their tutors can offer the right type of support (Hagenauer and Volet 2014). In the UK, all personal tutors undertake mandatory training (generally a half or full day workshop), and the National Union of Students (NUS) Charter on Personal Tutors (2006) set out 10 clear expectations of the personal tutoring scheme, which included: staff should be given full training on being an effective personal tutor, personal tutors should support both academic and personal development, and all students should meet their tutor at least once a term. However, this does not mean to say that tutors are sufficiently prepared to support students' wellbeing needs.

\section{Discussion: A new model of student support for wellbeing}

From our research findings, we can deduce that even though there are high degrees of satisfaction among students with respect to wellbeing:

- Students struggle with the workload and achieving a reasonable work-life balance which impacts upon their wellbeing

- The peer buddying/mentoring system is not robust enough to be effective

- The remit and role of wellbeing (student) officers requires organisation 
- Personal tutors do not all possess the right skills or work to the same exacting standards in delivering pastoral care

- There is a lack of clarity among students about who to trust and who assumes responsibility for their wellbeing

Concerns around student workload have been mentioned earlier in this paper, although part of the added difficulty is that a packed curriculum in engineering is seen as normal by students, meaning they are reluctant to seek support (Mirabelli et al. 2020). Engineering curriculums suffer from content overload, which also means the material is delivered in an often-repeated, fragmented way (Ktoridou and Eteokleous 2014). This situation needs changing, and as educators we need to seriously ask ourselves what can effectively be dumped-out of the curriculums we teach. In our own example, we have reduced the number of contact and independent study hours from 1500 to 1200 over the last year, for each academic year across the entire programme. This change has been made to accommodate the European Credit Transfer System (ECTS), which operates across Europe and was recently adopted by our institution. Reading weeks have been introduced without the added pressure of student deadlines to help alleviate stress (Agnew et al. 2019), and there is an additional hope that students will spend more time engaging with academic clubs and student societies - fostering communal and civic responsibility through a sense of belonging (Groccia 2018). Equally, conversations need to be had with students early on about workloads and managing expectations. Student perceptions are different from reality on engineering degree programmes, making it easy for students to fall behind and experience anxiety (Gerrard et al. 2017, Hassel and Ridout 2020). Students are not aware that they are required to be selfgoverning, especially in terms of how they manage their time and prioritise their work (Hassel and Ridout 2020). Therefore, these expectations must be known and addressed early on and should serve as an integral part of any introduction to the degree programme. Furthermore, a wellbeing plan has been suggested in literature (Crawford et al. 2016), which may be beneficial to students and staff alike.

As was mentioned earlier, peer mentoring is beneficial in maintaining wellbeing among students, although they need to develop a mature appreciation of what this entails and be willing to fulfil their responsibilities (Collings et al. 2014). Even though there is no definitive idea of what an ideal model of peer mentoring looks like, the following need to be established: features of a relationship, form of relationship, relationship structure and the forms of support offered (Crisp et al. 2017). In other words, ground rules need to be set and structure decided, so schemes are not ad-hoc in design and delivery with students' experiences being widely different from one another. With respect to more formalised support for wellbeing, students naturally turn to one another in moments of crisis, with recent literature suggesting that structured and directed peer support for wellbeing may provide an opportunity to engage students at an informal level and avoid some barriers to seeking help (Byrom 2018). The work of student wellbeing officers may prove beneficial, but good organisation structures are required. Adequate training and follow-up evaluation are necessary for the scheme to be effective (Crisp et al. 2020), but equally the student wellbeing officers need to be part of a holistic, joined-up approach to wellbeing. To this end, a professionally trained wellbeing advisor could play an instrumental role. Since beginning this research, a professional wellbeing advisor has been appointed in our department, with part of 
her remit being to organise this scheme and produce clear protocols associated with the behaviour, responsibilities, and main duties of the officers.

Personal tutors lack training in tutoring, and even though personal tutoring contributes significantly to student engagement, and in turn feelings of belonging, there is a disparity in quality among tutors (McFarlane 2016). Our research findings reflect this disparity with some students reportedly feeling uncomfortable with their appointed personal tutors, tutors not being able to provide helpful information, or adequate pastoral support. By and large, students expect their personal tutors to be empathetic, reliable, make them feel cared for, enthusiastic and approachable when delivering pastoral care (Grey and Osborne 2020). This is a tall order and not every tutor possesses these qualities, but equally personal tutors ought to be reflective enough to recognise gaps in the support they offer and be willing to take up opportunities for skills development as and when required. Furthermore, they ought to be aware and responsive to the emotional needs of students who generally feel more isolated, vulnerable and fragile than they have in previous generations (Patalay and Gage 2019), with mental health first aid training being available throughout HEIs in the UK to help personal tutors with skilling-up in this area.

Students mentioned trust and responsibility with regards to wellbeing; they were not always comfortable going to the individuals they had been told to seek out and were unsure where ultimate responsibility for their wellbeing needs lay. As mentioned earlier, trust is an important factor in wellbeing (Leighton et al. 2016). An initial analysis of the data has resulted in a dedicated wellbeing advisor being appointed in our department, which has helped greatly with countering some of the issues students identified around trust and responsibility. As expected, an additional level of support is offered to students directly and immediately, information and cues are channelled sensibly, and the individual provides a useful bridge between personal tutors and students (Crawford et al. 2016). Admittedly, there are cost implications associated with new appointments, but equally individuals could undertake specific targeted training and with some adjustment of role, fulfil the need for such a position.

By considering our findings and their associated implications in light of the conceptual framework on student engagement proposed by Kahu and Nelson, we are able to model wellbeing for an engineering programme of study through adapting their original framework (presented as Figure 3).

\section{[FIGURE 3 HERE]}

The model accommodates the key student support mechanisms reported on in this research. The importance of a balanced workload is key in maintaining a positive relationship between the student (motivations, learning goals etc.) and the university, affecting students in the educational interface. For example, students' wellbeing is negatively affected if the workload is considered too intense. Similarly, we have depicted tutorial and peer support as a connector between student wellbeing at the educational interface and immediate social outcomes 
(related to satisfaction and wellbeing), as the nature of student-tutor and student-peer relationships can positively influence students' reflections regarding their time at university. Two key indicators of wellbeing, trust and responsibility have been denoted as an area where the services of a staff wellbeing advisor could prove beneficial (in assuming responsibility and developing trust). Even though it does not inform part of the findings from this research, we would agree with Houghton and Anderson (2017), who refer to more subtle forms of building trust, for example the friendliness of administrators who are often overlooked, but are significant in students' minds as supporting their sense of belonging. Equally an immediate academic outcome ought to be that students are reflective learners rather than acquiring vast quantities of knowledge for the sake of it and learn to learn through occasional, term-time week long breaks, (resulting in less of a learning burden). Furthermore, the model points to specific interventions in the educational interface. Students self-efficacy could be improved if students offered more emotional support to one another through shared experiences. Emotional support could be garnered through more robust and organised forms of peer interaction, and students' sense of belonging enhanced if they were encouraged to engage in extra-curricular activities. Such a notion is also prevalent in literature suggesting that self-efficacy was enhanced through a connected, mutual and appreciative relationship between staff and students and between students and their peers (Micari and Pazos 2016).

\section{Concluding remarks}

In conclusion, this research shows that there is still important work to be done in supporting engineering students' wellbeing. Organisational structures need to be in place, individuals involved in administering support need to be professionally trained up, and the intensity of the workload reviewed. In light of the current COVID-19 outbreak, and the fact that students are likely to be accessing their education remotely for some time, there is more urgency in implementing these proposals to ensure students do not fall by the wayside. Additionally, we need to have a serious conversation about student expectations, with respect to workload, and how they can effectively manage their workload given they will not be directly under our care. As part of this, a wellbeing plan to accompany a study plan which is routinely reviewed with a personal tutor might be a significant step forward in building students' awareness and develop a self-help culture. Similarly, collective responsibility among students to keep an eye out for one another, is also greatly encouraged to build more informal mechanisms of peer support.

As suggested earlier, the current situation with respect to provisions for wellbeing is encouraging, and every HEI in the UK makes concerted efforts to support student wellbeing, with plans constantly under review. Dedicated wellbeing advisors are becoming more mainstream, but as a community of educators we need to be honest about our concerns and work collectively to solve the problems students face. This work contributes to the literature, as one of the few studies to explore wellbeing among engineering students, and we hope it opens up a more fruitful discussion on the issues presented here.

\section{References}


Adler, E. (2016), Becoming a student of English: students' experiences of transition into the first year, Arts and Humanities in Higher Education, 17(2): 185-203, https://doi.org/10.1177/1474022216628303

Agnew, M., Poole, H. and Khan, A. (2019), Fall break fallout: exploring student perceptions of the impact of an Autumn break on stress, Student Success Journal, 10(3): 45-54, https://doi.org/10.5204/ssj.v10i3.1412

Ahn, M.Y. and Davis, H.H. (2020), Four domains of students' sense of belonging to university, Studies in Higher Education, 45(3): 622-634, https://doi.org/10.1080/03075079.2018.1564902

Alzahem, A.M., van der Molen, H.T., Alaujan, A.H., Schmidt, H.G. and Zamakhshary, M.H. (2011), Stress amongst dental students: a systematic review, European Journal of Dental Education, 15(1): 8-18, https://doi.org/10.1111/j.1600-0579.2010.00640.x

Andrews, B. and Wilding, J.M. (2004), The relation of depression and anxiety to life-stress and achievement in students, British Journal of Psychology, 95(4): 509-521, https://doi.org/10.1348/0007126042369802

Ansari, W.E., Stock, C., Snelgrove, S., Hu X., Parke, S., Davies, S., John, J., Adetunji H., Stoate, M., Deeny P., Philips, C. and Mabhala, A. (2011), Feeling healthy? A survey of physical and psychological wellbeing of students from seven universities in the UK, International Journal of Environmental Research and Public Health, 8(5): 13081323, https://doi.org/10.3390/ijerph8051308

Braun, V. and Clarke, V. (2012). Thematic analysis. In H. Cooper, P. M. Camic, D. L. Long, A. T. Panter, D. Rindskopf, \& K. J. Sher (Eds.), APA handbooks in psychology®. APA handbook of research methods in psychology, Vol. 2. Research designs: Quantitative, qualitative, neuropsychological, and biological (p. 57-71). American Psychological Association. https://doi.org/10.1037/13620-004

Byrom, N. (2018), An evaluation of a peer support intervention for student mental health, Journal of Mental Health, 27(3): 240-246, https://doi.org/10.1080/09638237.2018.1437605

Collings, R., Swanson, V. and Watkins, R. (2014), The impact of peer mentoring on levels of student wellbeing, integration and retention: a controlled comparative evaluation of residential students in UK higher education, Higher Education, 68(6): 927-942, DOI 10.1007/s10734-014-9752-y

Costa, H., Ripoll, P., Sánchez, M. and Carvalho, C. (2013), Emotional intelligence and selfefficacy: effects on psychological wellbeing in college students, The Spanish Journal of Psychology, 16(E50): 1-9, https://doi.org/10.1017/sjp.2013.39

Crawford, N, Lisciandro J, Jones A, Jaceglav, M, McCall, D, Bunn, R, Cameron, H, Westacott, M \& Andersen, S (2016), 'Models of support for student wellbeing in enabling programs: comparisons, contrasts and commonalities at four Australian universities', FABENZ Conference, 1-2 December 2016, New Zealand 
Crisp, G., Baker, V.L., Griffin, K.A., Lunsford, L.G. and Pifer, M.J. (2017), Mentoring undergraduate students, ASHE Higher Education Report, 43(1), New Jersey: Wiley Periodicals Inc.

Crisp, D.A., Rickwood, D., Martin, B. and Byrom, N. (2020), Implementing a peer support program for improving university student wellbeing: the experience of program facilitators, Australian Journal of Education, 64(2): 113-126, https://doi.org/10.1177/0004944120910498

Crouch, M and McKenzie, H. (2006), The logic of small samples in interview-based qualitative research, Social Science Information, 45(4): 483-499, https://doi.org/10.1177/0529018406069584

Danowitz, A. and Beddoes, K, (2018), Characterising mental health and wellness in students across engineering disciplines, ASEE conference, June 2018

Field, J. (2009), Wellbeing and Happiness. Inquiry into the future of lifelong learning. Thematic paper 4. Leicester, UK. National Institute of Adult Continuing Education

Fitzpatrick, JJ., Byrne, E.P. and Kennedy, D. (2009), Making programme learning outcomes explicit for students of process and chemical engineering, Education for Chemical Engineers, 4(2): 21-28, https://doi.org/10.1016/j.ece.2009.07.001

Flick, U. (2007). Designing Qualitative Research. London, England: SAGE.

Forgeard, M., Jayawickreme, E., Kern, M. and Seligman, M. (2011), Doing the right thing: measuring wellbeing for public policy, International Journal of Wellbeing, 1(1): 79106, doi:10.5502/ijw.v1i1.15

Fredricks, J., Blumenfeld, P. and Paris, A. (2004), School engagement: potential of the concept, state of the evidence, Review of Educational Research, 74(1): 59-109, https://doi.org/10.3102/00346543074001059

Garmendia, M, Guisasola, J., Barragués, J.I. and Zuza, K. (2008), Estimate of students' workload and the impact of the evaluation system on students' dedication to studying a subject in first-year engineering courses, European Journal of Engineering Education, 33(4): 463-470, https://doi.org/10.1080/03043790802253657

Gerrard, M.D., Newfield, K., Asli, N.B. and Variawa, C. (2017), Are students overworked? Understanding the workload expectations and realities of first-year engineering, ASEE conference, June 2017

Godfrey, E. and Parker, L. (2010), Mapping the cultural landscape in engineering education, Journal of Engineering Education, 99: 5-22, https://doi.org/10.1002/j.21689830.2010.tb01038.x

Grey, D and Osborne, C. (2020), Perceptions and principles of personal tutoring, Journal of Further and Higher Education, 44(3): 285-299, https://doi.org/10.1080/0309877X.2018.1536258

Groccia, J.E. (2018), What is student engagement? New Directions for Teaching and Learning, 154: 11-20, Doi: 10.1002/tl.20287 
Hagenauer, G. and Volet, S.E. (2014) Teacher-student relationship at university: an important yet under-researched field, Oxford Review of Education, 40:3, 370-388, https://doi.org/10.1080/03054985.2014.921613

Hassel S and Ridout N (2018) An Investigation of First-Year Students' and Lecturers' Expectations of University Education, Frontiers in Psychology, 8:2218. doi: 10.3389/fpsyg.2017.02218

Houghton, A.M. and Anderson, J. (2017), Embedding Mental Wellbeing in the Curriculum: maximising success in higher education, Higher Education Academy: York, U.K.

Jungert, T. (2008). A longitudinal study of engineering students' approaches to their studies. Higher Education Research \& Development, 27(3), 201-214. doi: $10.1080 / 07294360802183770$

Kahu, E. (2013), Framing student engagement in higher education, Studies in Higher Education, 38(5): 758-773, https://doi.org/10.1080/03075079.2011.598505

Kahu, E., Nelson, K. and Picton, C. (2017), Student interest as a key driver of student engagement for 1st year students, Student Success, 8(2): 55-66, doi: 10.5204/ssj.v8i2.379

Kahu, E. R. and Nelson, K. (2017). Student engagement in the educational interface: understanding the mechanisms of student success. Higher Education Research and Development, 37(1), 58-71. https://doi.org/10.1080/07294360.2017.1344197

Kember, D. (2004), Interpreting student workload and the factors which shape students' perceptions of their workload, Studies in Higher Education, 29(2): 165-184, https://doi.org/10.1080/0307507042000190778

Ktoridou, D. and Eteokleous, N. (2014), Engineering education: time to reform the fragmented, content-overloaded curriculum context? IEEE Global Engineering Education Conference, April 2014, Doi: 10.1109/EDUCON.2014.6826121

Kvale, S. (1996), Interviews. London: Sage publications

Laidlaw, A., McLellan, J. and Ozakinci, G. (2016), Understanding undergraduate student perceptions of mental health, mental wellbeing and help-seeking behaviour, Studies in Higher Education, 41(12): 2156-2168, https://doi.org/10.1080/03075079.2015.1026890

Leighton, J. P., Seitz, P., Chu, M-W. and Bustos Gomez, M. C. (2016). Operationalizing the role of trust for student wellbeing, learning and achievement. International Journal of Wellbeing, 6(2), 57-79. doi:10.5502/ijw.v6i2.467

Malm, J., Bryngfors, L. and Morner, L.L. (2012), Supplemental instruction for improving first year results in engineering studies, Studies in Higher Education, 37(6): 655-666, https://doi.org/10.1080/03075079.2010.535610

Maunder, R.E. (2017), Students' peer relationships and their contribution to university adjustment: the need to belong in the university community, Journal of Further and Higher Education, 42(6): 756-768, https://doi.org/10.1080/0309877X.2017.1311996 
McFarlane, K.J. (2016), Tutoring the tutors: supporting effective personal tutoring, Active Learning in Higher Education, 17(1): 77-88, https://doi.org/10.1177/1469787415616720

Micari, M. and Pazos, P. (2016), Fitting in and feeling good: the relationships among peer alignment, instructor connectedness, and self-efficacy in undergraduate satisfaction with engineering, European Journal of Engineering Education, 41(4): 380-392, https://doi.org/10.1080/0343797.2015.1079814

Mirabelli, J.F., Kunze, A.J., Ge, J., Cross, K.J. and Jensen, K. (2020), Work in Progress: identifying factors that impact student experience of engineering stress culture, ASEE Virtual Conference, 22-26 June 2020

New Economics Foundation (2009), National Accounts of Wellbeing: bringing real wealth onto the balance sheet. London, UK: Author. http://cdn.media70.com/nationalaccounts-of-well-being-report.pdf

NUS (2006), NUS Charter on Personal Tutors, accessed 12.08.20, https://www.nusconnect.org.uk/resources/nus-charter-on-personal-tutors

Patalay, P. and Gage, S.H. (2019), Changes in millennial adolescent mental health and health-related behaviours over 10 years: a population cohort comparison study, International Journal of Epidemiology, 48(5): 1650-1664, https://doi.org/10.1093/ije/dyz006

Sebring, P. and Bryk, A. (2000), School leadership and the bottom line in Chicago. Phi Delta Kappan, 81(6), 440-443

Shaikh, B.T., Kahloon, A., Kazmi, M., Khalid, H., Nawaz, K., Khan, N.A. and Khan, S. (2004), Students, stress and coping strategies: a case of Pakistani medical school, Education for Health, 17(3): 346-353, Doi: 10.1080/13576280400002585

Smith A.P. (2019) Student Workload, Wellbeing and Academic Attainment. In: Longo L., Leva M. (eds) Human Mental Workload: Models and Applications. H-WORKLOAD 2019. Communications in Computer and Information Science, 1107: 35-47, https://doi.org/10.1007/978-3-030-32423-0_3

Stake, R.E. (1995), The Art of Case Study Research, Sage: Thousand Islands, London and New Delhi

Swart, A.J. and Hertzog, P.E. (2017), The impact of student unrest on freshmen engineering students in South Africa, IEEE Global Engineering Education Conference, 25-28 April 2017, doi: 10.1109/EDUCON.2017.7942941

Thurber, C.A. and Walton, E.A. (2012), Homesickness and adjustment in university students, Journal of American College Health, 60(5): 415-419, https://doi.org/10.1080/07448481.2012.673520

Verger, P., Combes, J., Kovess-Masfety, V., Choquet, M., Guagliardo, V., Rouillon, F. amd Peretti-Watterl, P. (2009), Psychological distress in first year university students: socioeconomic and academic stressors, mastery and social support in young men and 
women. Social Psychiatry and Psychiatric Epidemiology 44: 643-650

https://doi.org/10.1007/s00127-008-0486-y

World Health Organisation, (2012), Mental Health Action Plan 2013-2020, $66^{\text {th }}$ World Health Assembly, Manchester,

https://www.who.int/mental_health/publications/action_plan/en/

Yip, M.C.W. (2009), Differences between high and low academic achieving university students in learning and study strategies: a further investigation, Educational Research and Evaluation, 15(6): 561-570, https://doi.org/10.1080/13803610903354718

Zepke, N. (2013), Student engagement: a complex business supporting the first-year experience in tertiary education, The International Journal of the First Year in Higher Education, 4(2): 1-14, doi: 5204/intjfyhe.v4i2.183

Zepke, N. (2015), Student engagement research: thinking beyond the mainstream, Higher Education Research and Development, 34(6): 1311-1323, https://doi.org/10.1080/07294360.2015.1024635 


\begin{tabular}{|c|c|c|c|c|c|c|}
\hline & 1 & 2 & 3 & 4 & 5 & 6 \\
\hline $\begin{array}{l}\text { 1. Quality of tutorial support (r) } \\
\text { P value (p) }\end{array}$ & 1 & & & & & \\
\hline $\begin{array}{l}\text { 2. Mums \& Dads scheme (r) } \\
\text { P value (p) }\end{array}$ & $\begin{array}{l}0.228^{* *} \\
0.003\end{array}$ & 1 & & & & \\
\hline $\begin{array}{l}\text { 3. Organisation of programme }(r) \\
P \text { value }(p)\end{array}$ & $\begin{array}{l}0.275^{* *} \\
\mathrm{p}<0.000\end{array}$ & $\begin{array}{l}0.390^{* *} \\
\mathrm{p}<0.000\end{array}$ & 1 & & & \\
\hline $\begin{array}{l}\text { 4. Support for workload }(r) \\
\text { P value (p) }\end{array}$ & $\begin{array}{l}0.147 \\
0.054\end{array}$ & $\begin{array}{l}0.165^{*} \\
0.030\end{array}$ & $\begin{array}{l}0.102 \\
0.181\end{array}$ & 1 & & \\
\hline $\begin{array}{l}\text { 5. Support for wellbeing }(r) \\
P \text { value }(p)\end{array}$ & $\begin{array}{l}0.410^{* *} \\
\mathrm{p}<0.000\end{array}$ & $\begin{array}{l}0.273 * * \\
p<0.000\end{array}$ & $\begin{array}{l}0.401^{* *} \\
\mathrm{p}<0.000\end{array}$ & $\begin{array}{l}0.408 * * \\
p<0.000\end{array}$ & 1 & \\
\hline $\begin{array}{l}\text { 6. Peer interaction }(r) \\
P \text { value }(p)\end{array}$ & $\begin{array}{l}0.134 \\
0.080\end{array}$ & $\begin{array}{l}0.287 * * \\
p<0.000\end{array}$ & $\begin{array}{l}0.264 * * \\
p<0.000\end{array}$ & $\begin{array}{l}0.414 * * \\
p<0.000\end{array}$ & $\begin{array}{l}0.402 * * \\
\mathrm{p}<0.000\end{array}$ & 1 \\
\hline
\end{tabular}

** Correlation is significant at the 0.01 level (2-tailed)

* Correlation is significant at the 0.05 level (2-tailed)

Table 1: P-values and correlation coefficients of the 6-item scale on student support and related mechanisms 
Sociocultural context

Polical and social environment
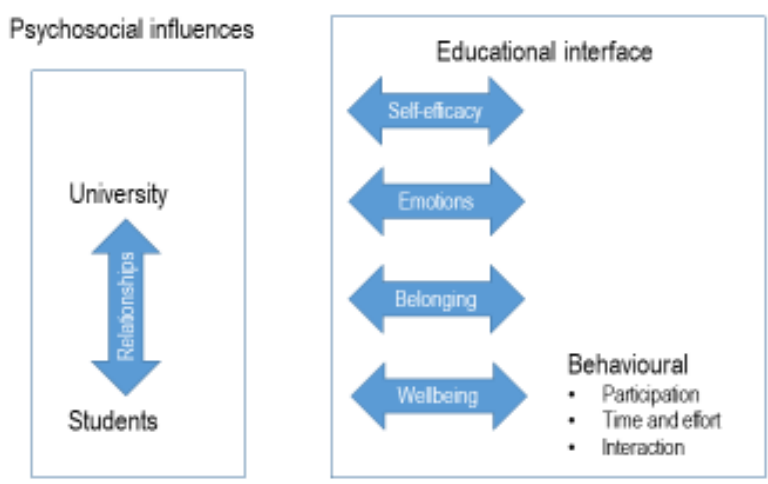

Immediate outcomes

\begin{tabular}{|l|}
\hline Academic \\
- Skils \\
Krowladga \\
\\
\\
\\
Social \\
- Satsfaction \\
\end{tabular}

Figure 1 


\section{Percentages of students who responded to 6 items on tutorial support and wellbeing}

I am satisfied with the amount of social interaction I have with peers

I feel that appropriate measures are in place to support my wellbeing

I feel I can balance my workload with extra-curricular activities

I am satisfied with the organisation of the programme (e.g. ratio of lectures to independent study)

I find that the mums and dads system in place works well

I am satisfied with the quality of support I receive from my personal tutor

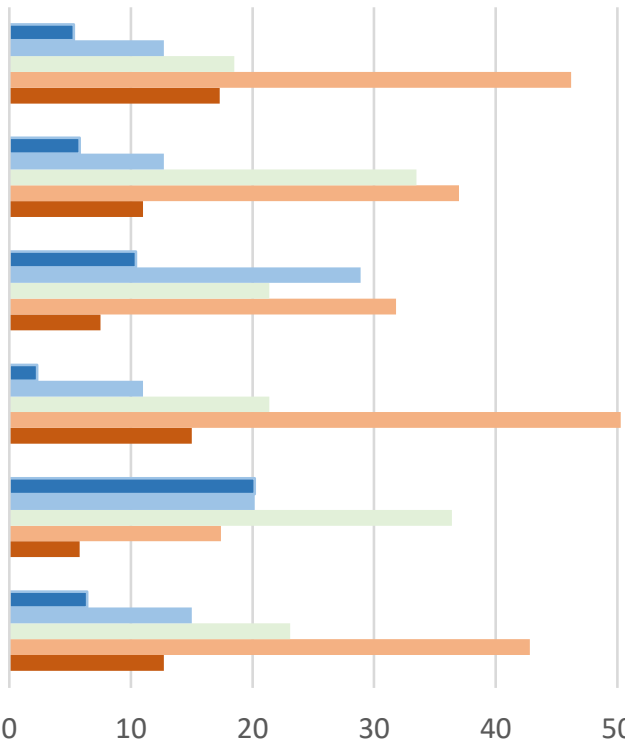

Figure 2 
Sociocultural context

Poltical and social environment

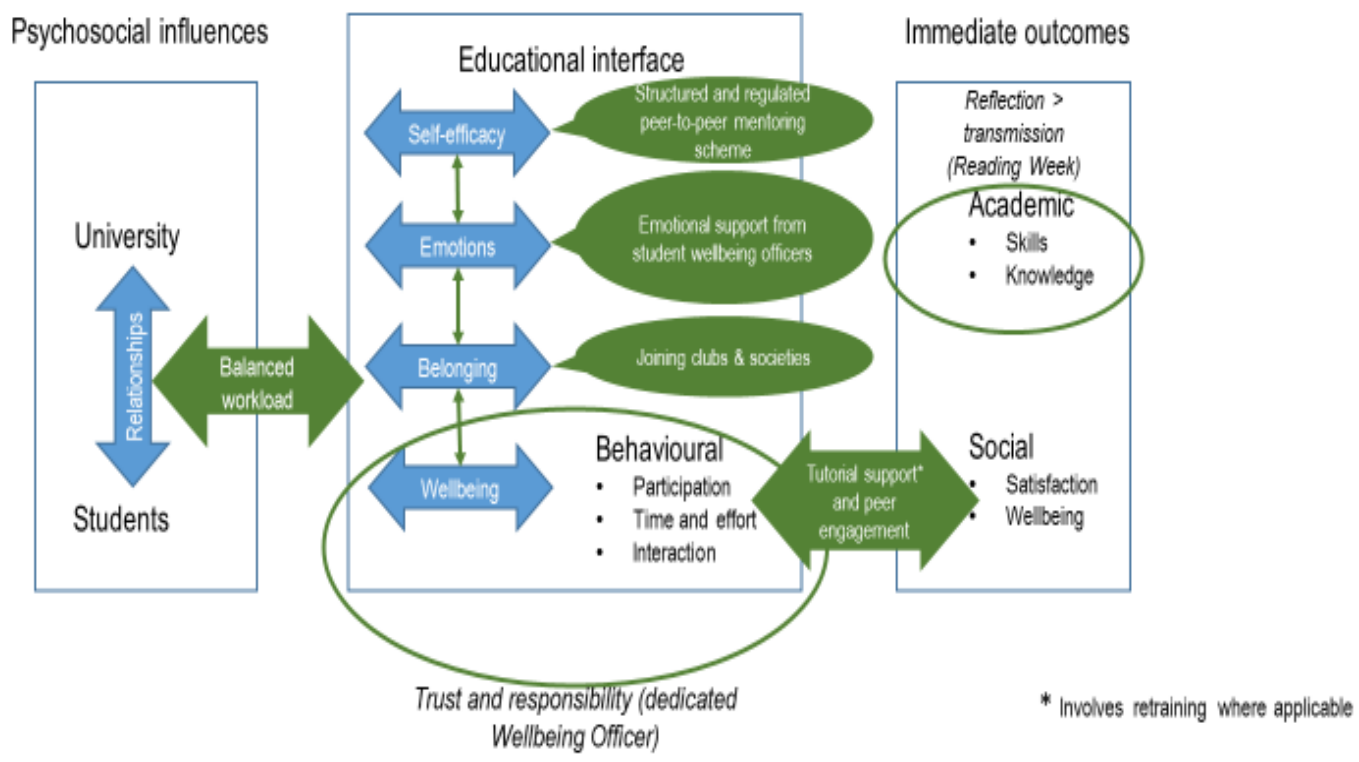

Figure 3 


\section{List of Figures}

Figure 1: Adapted version of Kahu and Nelson's conceptual framework of student support (2017)

Figure 2: $\quad$ Graph showing percentages of students who agreed/disagreed with 6 items on student support mechanisms

Figure 3: $\quad$ Schematic model adapted from Kahu and Nelson's student support framework for an engineering programme of study at a research intensive HEI 